\title{
Cerebral blood flow velocity changes after rapid administration of surfactant
}

\author{
F Cowan, A Whitelaw, D Wertheim, M Silverman
}

\begin{abstract}
A computer linked Doppler system was used to make continuous measurements of cerebral blood flow velocity (CBFV) from the middle cerebral artery, mean arterial blood pressure (MAP) from the umbilical artery, and heart rate before, during, and for 20 minutes after the endotracheal administration of $200 \mathrm{mg} / \mathrm{kg}$ of porcine surfactant in 10 preterm infants with respiratory distress syndrome.

Within two minutes of surfactant administration, there was a median fall of $6 \mathrm{~mm} \mathrm{Hg}$ (15\%) fall in MAP and $36 \%$ in CBFV. There was a change in the Doppler spectra with almost complete loss of diastolic velocities. A rapid reduction in pulmonary vascular resistance with consequent left to right ductal shunting is one possible cause. These acute changes in MAP and CBFV after bolus surfactant administration may increase the risk of intraventricular haemorrhage.
\end{abstract}

There is evidence that surfactant replacement therapy can reduce mortality and pulmonary complications in preterm infants with respiratory distress syndrome. ${ }^{1}$ However, Horbar et al reported a large multicentre randomised trial with a significantly increased number of severe periventricular haemorrhages among infants receiving bovine surfactant compared with control infants. ${ }^{2}$ The Collaborative European Multicentre Study of Curosurf (porcine surfactant) found a surprisingly high incidence (26\%) of severe intraventricular haemorrhage despite a big reduction in mortality and bronchopulmonary dysplasia among surfactant treated infants. ${ }^{1}$ Other randomised trials have found a reduction in intraventricular haemorrhage among surfactant treated infants. ${ }^{34}$.

The bolus administration of surfactant into the trachea disturbs ventilation and could theoretically cause acute changes in pulmonary compliance, blood gases, pulmonary vascular resistance, blood pressure, and heart rate. Such changes, together with possible shunting through the ductus arteriosus, could have major effects on the cerebral circulation. Previous studies of the physiological changes during and after surfactant have attempted to examine these questions. All have found a rapid improvement in arterial oxygen tension $\left(\mathrm{PaO}_{2}\right)$. Halliday et al found evidence for increased pulmonary compliance but no increase in pulmonary blood flow. ${ }^{5}$ The same group used intermittent (every 15 minutes) Doppler measurements of peak flow velocity averaged over 10-15 cardiac cycles. ${ }^{6}$ There was no significant difference between surfactant treated infants and controls in cerebral blood velocities measured on the internal carotid or pericallosal arteries. Jorch $e t$ al examined the effect of prophylactic natural surfactant on cerebral blood velocity in the internal carotid artery. ${ }^{7}$ These measurements were made at intervals of 10 minutes before and after surfactant treatment. There was no significant trend overall in cerebral blood velocity, arterial pressure, or carbon dioxide tension $\left(\mathrm{PCO}_{2}\right)$ when the surfactant treated infants were compared to control infants.

Heldt $e t$ al examined circulatory changes after human surfactant treatment using ultrasound Doppler colour flow mapping in a blind randomised study. ${ }^{8}$ The ductus arteriosus was patent in all the infants at entry to the study but left to right shunting was more common in the surfactant treated group. They concluded that surfactant reduced pulmonary vascular resistance, thereby facilitating shunting but had no intrinsic effect on ductal closure.

In the light of these uncertainties about an increased incidence of severe intraventricular haemorrhage and possible adverse effects on the preterm cerebral circulation of rapidly changing blood gases, blood pressure, and ductal shunting, we have carried out a study of the acute physiological changes during and after surfactant therapy using continuous measurement of cerebral blood flow velocity (CBFV), mean arterial pressure (MAP), heart rate, and blood gas tensions.

\section{Patients and methods}

Ten preterm infants with a clinical and radiological diagnosis of respiratory distress syndrome were studied. They were all being mechanically ventilated with an inspired oxygen concentration of $60 \%$ or greater and were paralysed with pancuronium and sedated with pethidine. Their median birth weight was $935 \mathrm{~g}$ (range 712-1660). Their median gestational age was 27.5 weeks (range $26-30$ weeks). In all cases the parents gave informed consent to surfactant administration and the physiological measurements, and the protocol had been approved by the research ethics committee of the Hammersmith and Queen Charlotte's Special Health Authority. Median age at surfactant adminstration was 11.5 hours with a range of 7 to 72 hours.

Curosurf, a porcine natural surfactant (Chiesi Farmaceutici), was given in a total dose of 200 $\mathrm{mg} / \mathrm{kg}(2.5 \mathrm{ml} / \mathrm{kg})$ divided into two, by bolus injection through a 5 French gauge feeding catheter inserted down the endotracheal tube, which was temporarily disconnected from the ventilator. In the first six infants the first half 
dose was given with the head turned to the left side so that the catheter would tend to go down the right main bronchus. The ventilator was reconnected and when the infant had stabilised after about 30 seconds, the second half dose was given with the head turned to the right side, so that the catheter would tend to go down the left main bronchus. ${ }^{9}$ This head turning procedure necessitated a break in the CBFV measurements for about 15 seconds. The last four infants received surfactant with the head being held still in the midline so that CBFV measurements could be made continuously during instillation. One infant received surfactant $200 \mathrm{mg} / \mathrm{kg}$ on two separate occasions because of relapse after the first dose. Physiological measurements were thus made on 11 surfactant treatments.

In order to examine the effect of procedure independently of surfactant, measurements were made in one infant during disconnection from the ventilator and instillation of $2.5 \mathrm{ml} / \mathrm{kg}$ of $0.9 \%$ sodium chloride (saline) solution. This infant subsequently received surfactant. Saline administration was not studied in subsequent infants because of concern about a deterioration in their already critical condition.

\section{Physiological measurement techniques}

CBFV was measured using the duplex Doppler Vingmed CFM 700 system (Vingmed Sound A/S, Horten, Norway). Recordings were taken from the middle cerebral artery insonated via the temporal window. The position of the artery was first visualised using the imaging system and then blood velocities measured at an angle as close to zero as possible and at a measured depth. Thereafter, measurements were always made at the same angle and depth. An angle of zero was assumed for the calculation of intensity weighted mean velocity per consecutive heart beat. An electrocardiogram (ECG) recorded the heart rate.

The CFM 700, using a spectrum based velocity estimator, calculated the mean of the spectrum as the 50th percentile of the total spectral power each 10 milliseconds. The CFM 700 was interfaced to an Apricot XI computer (ACT Computers, Birmingham, England) which ran the Blood Velocity Analysis Program (Andiamo A/S, Oslo, Norway). ${ }^{10}$ This system calculated and stored on-line the time averaged velocities for each cardiac cycle (CBFV) together with heart rate and MAP.

MAP was measured continuously via an umbilical artery catheter, pressure transducer (Medex) and monitor (Tektronix). The pressure transducer's zero reading was checked at the start of each study. Arterial blood velocity spectra, arterial pressure waveform, and ECG were all stored on videotape.

We made a continuous recording of blood velocity, arterial pressure, and heart rate during a stable period before the bolus injection, during the surfactant adminstration, and intermittently up to 20 minutes afterwards. Pourcelot's resistance index (PI) was calculated:

$\mathrm{PI}=\frac{\text { peak systolic velocity }- \text { end diastolic velocity }}{\text { peak }}$ peak systolic velocity

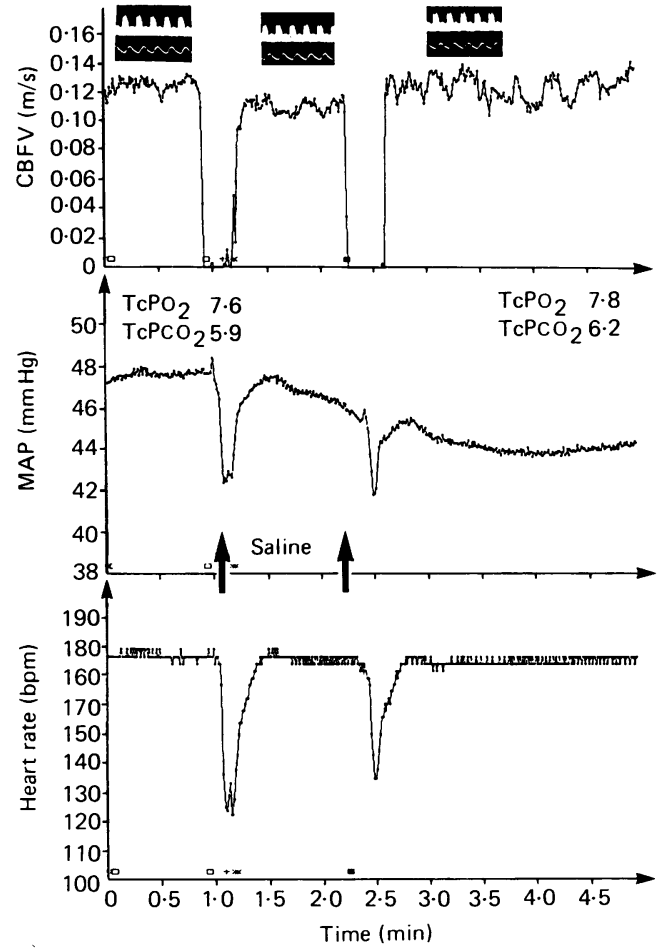

Figure 1 Simultaneous recording of middle cerebral artery $C B F V, M A P$, and heart rate over a five minute period. The arrows indicate the timing of endotracheal administration of
$2 \times 1.25 \mathrm{ml} / \mathrm{kg} 0.9 \%$ sodium chloride (saline) in a preterm infant with respiratory distress syndrome. Representative Doppler spectra are shown (inserts) with no change in the diastolic velocities.

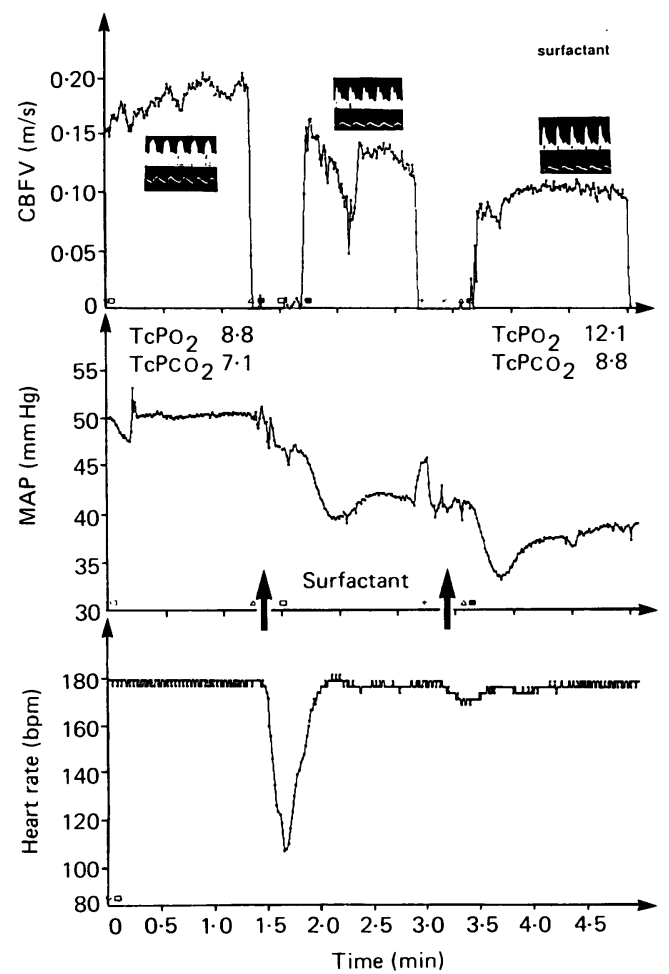

Figure 2 Simultaneousrecording of $C B F V, M A P$, and heart rateover a five minute period. The arrows indicate the timing of endotracheal adminstration of $2 \times 1.25 \mathrm{ml} / \mathrm{kg}$ sufactant in a preterm inf ant with respiratory distress syndrome. Representative Dopplerspectra are shown (inserts) with a large drop in the diastolic velocities. 
Transcutaneous $\mathrm{Po}_{2}$ and $\mathrm{PCO}_{2}$ were measured using a TCM3 system (Radiometer) to follow trends but direct arterial blood gas measurements before and five, 10 , and 20 minutes after surfactant administration were used to assess the effects of surfactant. Statistical comparisons of data used the paired Student's $t$ test where the distributions were Gaussian and the Wilcoxon signed rank test where the distributions were non-Gaussian.

\section{Results}

INDIVIDUAL RECORDINGS

During disconnection and instillation of saline in one infant (fig 1), there was an acute 4 to $5 \mathrm{~mm} \mathrm{Hg}(10 \%)$ fall in MAP, eventually settling $3 \mathrm{~mm} \mathrm{Hg} \mathrm{(7 \% )} \mathrm{below} \mathrm{the} \mathrm{starting} \mathrm{value,} \mathrm{and} \mathrm{a}$ brief 40 to 50 beats/ minute (bpm) fall in heart rate. The CBFV, although showing variability, was unchanged after the saline. The velocity spectrum of CBFV was unchanged by disconnection and saline adminstration, with no loss of diastolic velocity.

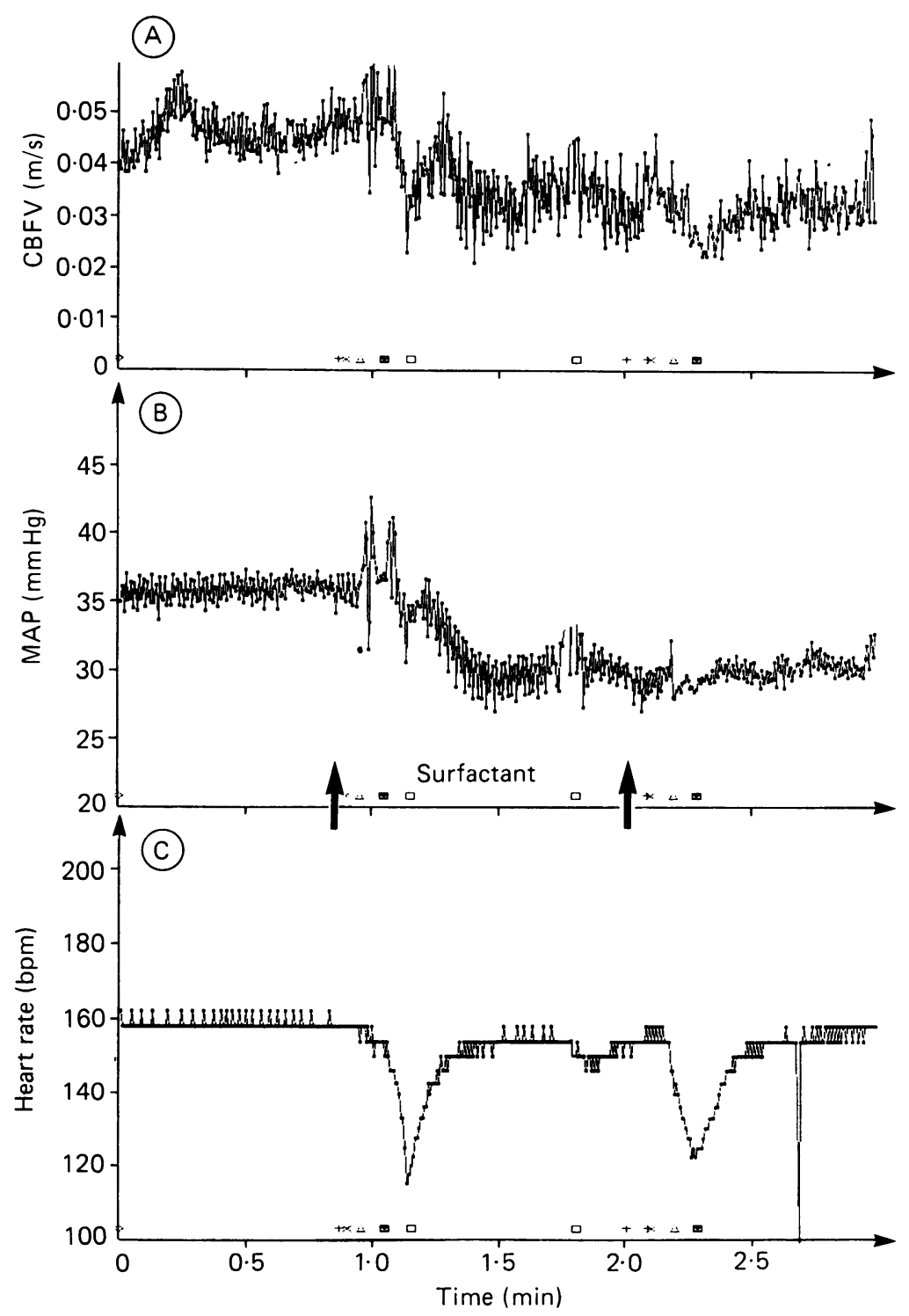

Figure 3 Continuous recording of middle cerebral artery $C B F V, M A P$, and heart rate during administration of $2 \times 1 \cdot 25 \mathrm{ml}$ surfactant (timing indicated by the arrow).
In the same infant there was a drop in heart rate at the first dose of surfactant but not at the second surfactant treatment (fig 2). MAP fell from $50 \mathrm{~mm} \mathrm{Hg}$ to about $40 \mathrm{~mm} \mathrm{Hg}$ after the first dose and then fell to about $35 \mathrm{~mm} \mathrm{Hg}$ after the second dose. This fall in MAP (greater than $20 \%$ ) was much greater than that seen after saline and persisted for at least 20 minutes. CBFV fell from $0.18 \mathrm{~m} / \mathrm{sec}$ and remained at 0.1 $\mathrm{m} / \mathrm{sec}$ ( $44 \%$ fall). The velocity spectrum shows a complete change of shape with a huge reduction in diastolic velocities. Figures 1 and 2 show the administration of saline and surfactant respectively with head turning necessitating two gaps in the velocity recordings.

Figure 3 shows a continuous recording made during surfactant administration with the head held steady in the midline with the infant supine. There were two brief bradycardias while the endotracheal tube was disconnected. The falls in MAP (about 15\%) and CBFV (nearly 40\%) persisted until the end of the recording.

\section{POOLED MEASUREMENTS}

Median initial change in MAP during all 11 surfactant administrations was $-6 \mathrm{~mm} \mathrm{Hg}$ with a range of +2 to $-17 \mathrm{~mm} \mathrm{Hg}$, only one infant showing a small initial rise in MAP (fig 4A). Before surfactant administration, MAP had a mean (SD) of $38 \cdot 1(6.9) \mathrm{mm} \mathrm{Hg}$. At two minutes mean MAP was $31.4(3.9) \mathrm{mm} \mathrm{Hg}$, by five minutes $33.6(3.2) \mathrm{mm} \mathrm{Hg}$, and at 10 minutes $34 \cdot 1 \mathrm{~mm} \mathrm{Hg}$. MAP was still reduced 20 minutes after administration in nine cases, with a median change of $-5 \mathrm{~mm} \mathrm{Hg}$ and a range of +6 to $-10 \mathrm{~mm} \mathrm{Hg}$. Mean values for MAP at two, five, 10 , and 20 minutes were all significantly lower than the presurfactant value $(\mathrm{p}<0.01$ in all cases). Mean change in heart rate was -35 with a range of +5 to $-102 \mathrm{bpm}$, but these changes were transient and resolved within five minutes (fig 4B).

There was a substantial initial reduction in CBFV in nine of the 11 cases (median change $-36 \%$, range $+11 \%$ to $-55 \%$ ) (fig $5 \mathrm{~A}$ ). Median CBFV before surfactant was $0.056 \mathrm{~m} / \mathrm{sec}$ (range $0 \cdot 03-0 \cdot 184$ ). During surfactant administration, median CBFV fell to $0.035 \mathrm{~m} / \mathrm{sec}$ (range $0.03-0.084)$ and at five minutes the median was $0.042 \mathrm{~m} / \mathrm{sec}$ (range $0.02-0 \cdot 1$ ). These values for CBFV were significantly lower than the presurfactant values $(\mathrm{p}<0.01$ in both cases). CBFV values at 20 minutes, median $0.048 \mathrm{~m} / \mathrm{sec}$ (range $0 \cdot 03-0.11$ ) were not significantly different from the presurfactant values $(p=0 \cdot 16)$ but there was still considerable scatter in individual cases, median change from the presurfactant value being $-24 \%$ with a range of $+44 \%$ to $-39 \%$. Three infants had CBFV values at 20 minutes that were higher than those before surfactant.

Peak systolic velocity in the middle cerebral artery was maintained during surfactant administration but there was a reduction to zero in end diastolic velocity in seven of the 11 cases by two minutes and 10 of the 11 by five minutes (fig 5B). This is the type of change shown in an individual infant in figure 2. Two of the infants had zero end diastolic velocity before surfactant administration and this persisted. Diastolic 

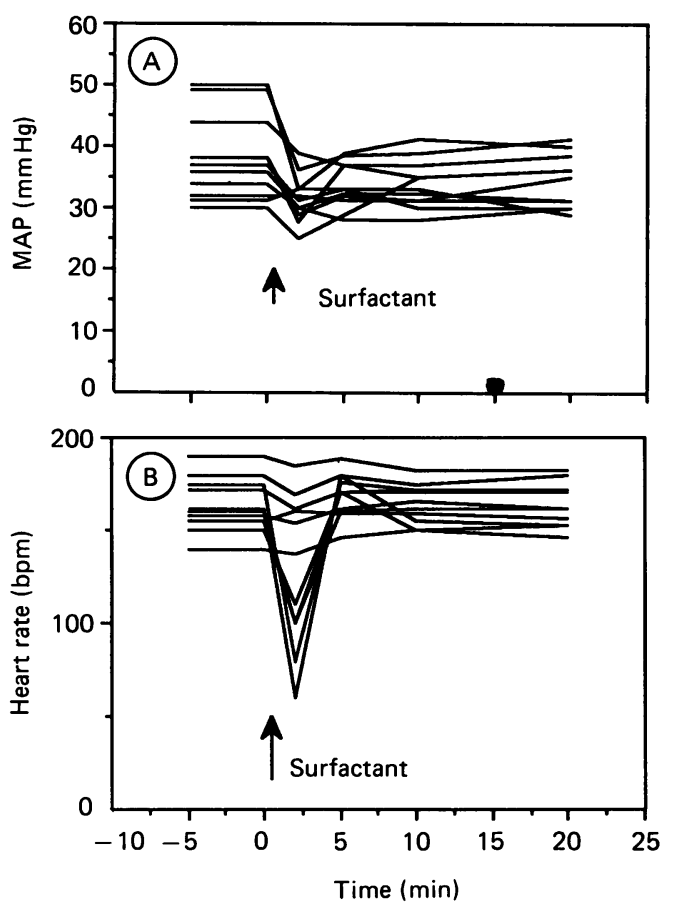

Figure4 MAPand heart ratefrom all 11 surfactant treatments: (A) shows, a significant and sustained drop in $M A P$ and $(B)$ only a transient decrease in heart rate.
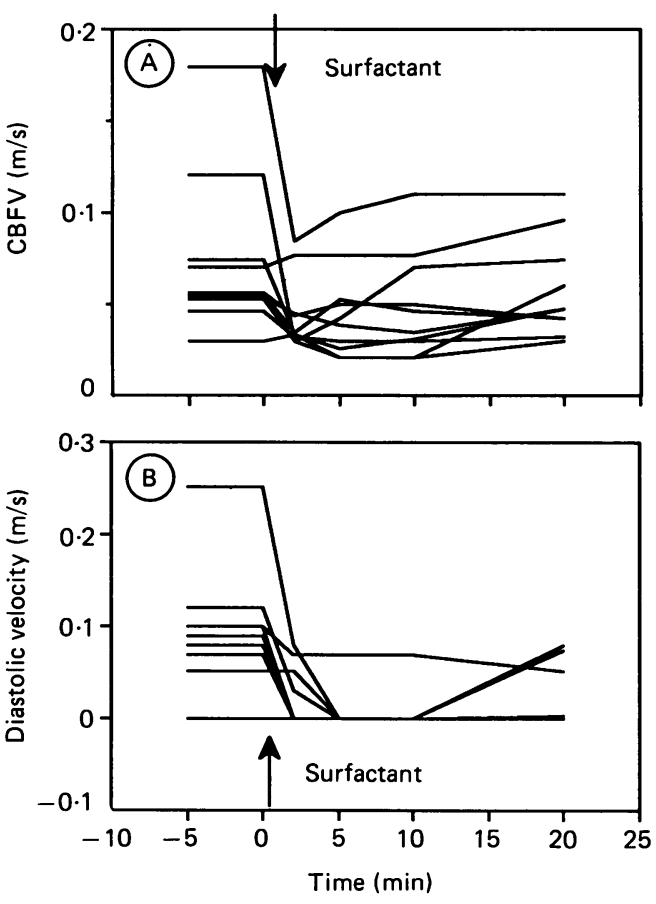

Figure 5 (A) Middle cerebral artery CBFV from all 11 surfactant treatments. There was a significant reduction during surfactant administration and at five minutes. $(B)$ Diastolic velocities from the middle cerebral artery of all 11 surfactant treatments. In two cases the diastolic velocity was 0 even before surfactant treatment.

velocities at two and five minutes were significantly different from presurfactant values ( $p<0.01$ in both cases). By 20 minutes, four of the infants had positive diastolic velocities (fig 5B). Pourcelot's resistance index rose from a median of 0.68 before surfactant to a median of 1.0 ( $p<0.01$ at two and five minutes).

Arterial $\mathrm{Po}_{2}$ showed a rapid increase from a mean (SD) of $7.5 \mathrm{kPa}$ to a mean (SD) of 13.7 $(4 \cdot 8) \mathrm{kPa}$ five minutes after surfactant $(p=0.002)$. After this time the inspired oxygen concentration was reduced to prevent hyperoxia. $\mathrm{PCO}_{2}$ rose from a mean (SD) of $5 \cdot 15(0 \cdot 80) \mathrm{kPa}$ to a mean (SD) of $5.39(0.89) \mathrm{kPa}$ five minutes after surfactant $(p<0.05)$. By 10 and 20 minutes mean $\mathrm{PCO}_{2}$ had returned to baseline value without a change in the ventilator settings.

\section{Discussion}

Using continuous recording of CBFV before, during, and after surfactant administration, this study showed a significant fall in velocities, and, by inference, cerebral blood flow, immediately after and for five minutes after surfactant treatment. By 20 minutes $\mathrm{CBFV}$ had returned to baseline levels in some cases. Simultaneous recording of MAP via an indwelling arterial catheter showed a significant fall persisting to 20 minutes. Heart rate fell transiently but recovered quickly.

The persistent though modest reduction in MAP might have been due to increased transmission of high airway pressure to the circulation, thus impeding venous return. Alternatively, the drop in MAP could be an effect of a widened pulse pressure resulting from left to right ductal shunting (see below) or a direct pharmacological effect of surfactant. We have noticed some flushing after porcine surfactant suggesting a peripheral vasodilator effect of one of its constituents. Whatever the cause, a considerable drop in MAP is undesirable as early hypotension has been shown to be a risk factor for intraventricular haemorrhage. ${ }^{11}$

The fall in mean CBFV could be explained by the immediate drop in MAP and by the fall in end diastolic velocity with maintenance of peak systolic velocity (fig 5B). Before treatment with surfactant all the infants had two resting recordings of CBFV and MAP to determine whether CBFV varied with changes in MAP or not. In two infants no spontaneous alterations in MAP occurred during these recordings and hence it was not possible to draw any conclusions. In the other eight infants only one showed any ability to maintain a stable CBFV in the face of changing MAP. Thus seven of the eight infants in whom it was possible to make a judgment probably had poor or absent cerebral autoregulation as one might expect at this range of gestational age ${ }^{12}$ and one would expect changes in MAP to be reflected in CBFV.

The striking loss of diastolic velocities is consistent with a sudden reduction in pulmonary artery pressure allowing left to right shunting through the patent ductus arteriosus and a cerebral steal phenomenon. ${ }^{13}$ Whether sudden changes to ductal shunting or cerebral steal can increase the risk of intraventricular haemorrhage is not known. It could be suggested that surfactant increases lung compliance and so allows the high airway pressure to exert its effect on the circulation. However, the rapidity and short duration of the CBFV changes together with the failure of $\mathrm{PCO}_{2}$ to decrease 
would be against improvement in lung compliance being the major mechanism behind the changes we have observed.

Previous attempts at investigating the effect of surfactant on the cerebral circulation have used very brief (4-6 seconds) recordings every $10-15$ minutes. ${ }^{67}$ Our continuous recordings around the time of surfactant therapy have shown that there are appreciable swings in CBFV, MAP, and heart rate which would probably have been missed with intermittent measurements. The noticeable changes in heart rate and MAP may be partly, but not entirely, explained by disconnection from the positive pressure oxygen and the rapid decrease in alveolar oxygen. The sheer volume of the endotracheal bolus $(2.5 \mathrm{ml} / \mathrm{kg})$ is likely to have a temporary obstructive effect and many infants did show a transient rise in $\mathrm{PCO}_{2}$. The manipulation involved in turning the head probably disturbs the infants, but this cannot be the major factor as the effects of an equivalent volume of saline (figs 1 and 2) were minor compared with the instillation of surfactant.

Most infants had a small and transient rise in $\mathrm{PCO}_{2}$ after surfactant and also an appreciable and persistant rise in $\mathrm{Po}_{2}$. Increasing $\mathrm{PCO}_{2}$ is usually, but not always, associated with a rise in CBFV. ${ }^{14}{ }^{15}$ Hyperoxia has been found to have extremely small effect in reducing CBFV, and the rise in $\mathrm{PO}_{2}$ after surfactant could not have produced the large fall in CBFV found. ${ }^{16}$

In view of the considerable increase in intraventricular haemorrhage reported by Horbar $e t$ $a l$ and the association between hypotension ${ }^{11}$ and fluctuations in $\mathrm{CBFV}^{17}$ and haemorrhage, it could be that the acute changes in the cerebral circulation related to surfactant administration might increase the risk of intraventricular haemorrhage. The effects on the systemic and cerebral circulation might be reduced by slower continuous infusion of surfactant without physical disturbance to the infant and the use of an endotracheal connector with a side arm for the infusion to avoid disconnection, bolus injection, and interruption of ventilation.
Dr Cowan and Dr Wertheim were supported by the Medical Research Council. We are grateful to Dr Bengt Robertson, Karolinska Insitute, Stockholm, for supplying the surfactant.

1 Collaborative European Multicenter Study Group. Surfactant replacement therapy for severe neonatal respiratory distress syndrome: an international randomised clinical trial. Pediasyndrome: an internation

2 Horbar JD, Soll RF, Schachinger $\mathrm{H}$, et al. A European multicenter randomised controlled trial of single dose surfactant therapy for idiopathic respiratory distress syndrome. Eur $\mathfrak{F}$ therapy for idiopathic respira

3 Enhorning G, Sheenan A, Possmeyer F, Dunn M, Chen CP, Milligan J. Prevention of neonatal respiratory distress syn drome by tracheal instillation of surfactant: a randomised trial. Pediatrics 1985;76:145-53.

4 McCord FB, Curstedt T, Halliday HL, McClure G, Reid M McC, Robertson B. Surfactant treatment and incidence of interventricular haemorrhage in severe respiratory distress syndrome. Arch Dis Child 1988;63:10-6.

5 Halliday H, McCord FB, McClure G, Reid M McC. Acute effects of instillation of surfactant in severe respiratory distress syndrome. Arch Dis Child 1989;64:13-6.

6 McCord FB, Halliday HL, McClure G, Reid M McC. Changes in pulmonary and cerebral blood flow after surfactant treatment for severe respiratory distress syndrome. In: tant treatment for severe respiratory distress syndrome. In: on Surfactant Replacement Therapy. Berlin: Springeron Surfactant

7 Jorch G, Rabe H, Garbe M, Michel E, Gortner L. Acute and protracted effects of intratracheal surfactant application on internal carotid carotid blood flow velocity, blood pressure and carbon dioxide tension in very low birth weight infants. Eur $\mathcal{F}$ Pediatr 1989;148:770-3.

8 Heldt GP, Pesonen E, Merritt TA, Elias W, Sahn DJ. Closure of the ductus arteriosus and mechanics of breathing in preterm infants after surfactant replacement therapy. Pediatr Res 1989;25:305-10.

9 Placzek M, Silverman $M$. Selective placement of bronchia suction catheters in intubated neonates. Arch Dis Child 1983;58:829-30.

10 Eriksen M, Kjaernes M. BVA-blood velocity analysis. Research Report 123. Oslo: Department of Informatics, University of Oslo, 1989.

11 Miall-Allen VM, De Vries LS, Whitelaw AGL. Mean arterial pressure and neonatal cerebral lesions. Arch Dis Child 1987; 62:1066-9.

12 Cowan F, Eriksen M, Wertheim DPF. Regulation of cerebral blood flow in the newborn infant. $\mathcal{F}$ Physiol 1989;417:P13.

13 Dean Wilcox W, Carrigan TA, Dooley KJ, et al. Range-gated pulsed Doppler ultrasonographic evaluation of carotid pulsed Doppler ultrasonographic evaluation of carotid ductus arteriosus. $\mathcal{F}$ Pediatr 1983;102:294-8.

14 Levene MI, Shortland D, Gibson N, Evans DH. Carbon dioxide reactivity of the cerebral circulation in extremely premature infants: effects of postnatal age and indomethacin. Pediatr Res 1988;24:175-9.

15 Greisen G, Trojaberg W. Cerebral blood flow, $\mathrm{PaCO}_{2}$ changes, and visual evoked potentials in mechanically ventilated preterm infants. Acta Paediatr Scand 1987;76 $394-400$.

16 Niijima S, Shortland DB, Levene MI, Evans DH. Transient hyperoxia and cerebral blood flow velocity in infants born prematurely and at full term. Arch Dis Child 1988;63: 1126-30.

17 Perlman JM, McMenamin JB, Volpe JJ. Fluctuating cerebral blood flow velocity in respiratory distress syndrome. $N E n g l f$ Med 1983;309:204-8. 